\title{
FEAR IN THE NEWS: A Discourse of Control
}

\author{
David L. Altheide \\ R. Sam Michalowski \\ Arizona State University
}

\begin{abstract}
Fear pervades popular culture and the news media. Whether used as a noun, verb, adverb, or adjective, an ongoing study finds that the word "fear" pervades news reports across all sections of newspapers, and is shown to move or "travel" from one topic to another. The use of fear and the thematic emphases spawned by entertainment formats are consistent with a "discourse of fear," or the pervasive communication, symbolic awareness and expectation that danger and risk are a central feature of the effective environment. A qualitative content analysis of a decade of news coverage in The Arizona Republic and several other major American news media (e.g., the Los Angeles limes, and $\mathrm{ABC}$ News) reveals that the word "fear" appears more often than it did several years ago, particularly in headlines, where its use has more than doubled. Comparative materials obtained through the Lexis/Nexis information base also reveals that certain themes are associated with a shifting focus of fear over the years (e.g., violence, drugs, AIDS), with the most recent increases associated with reports about children. Analysis suggests that this use of fear is consistent with popular culture oriented to pursuing a "problem frame" and entertainment formats, which also have social implications for social policy and reliance on formal agents of social control.
\end{abstract}

No passion so effectually robs the mind of all its powers of acting and reasoning as fear.

Edmund Burke

Nearly everyone knows how to read the news of the day. But using news as a resource for everyday life is different from treating it as a topic to understand how social reality is ordered, maintained, and repaired. On the one hand, news reports as resources serve to set emotional tones for the rhythms of life and reminders of ideals of the order and disorder that threaten peaceful neighborhoods and the cosmologies of "normal order." On the other hand, news reports as topics provide a window into organizational frameworks of reality maintenance and their relevance for broader societal definitions of situations, courses of action, and assessments of a lifeworld. News reports, as a feature of popular culture, become intertwined in everyday life, political speeches, and other entertainment forms such as movies. This article reports on the way fear is being used to provide entertaining news that also benefits formal

Direct all correspondence to David L. Altheide, School of Justice Studies, Arizona State University, Tempe, AZ 85287-0403; e-mail: David.Altheide@Asu.edu

The Sociological Quarterly, Volume 40, Number 3, pages 475-503.

Copyright @ 1999 by The Midwest Sociological Society.

All rights reserved. Send requests for permission to reprint to:

Rights and Permissions, University of California Press, Journals Division, 2120 Berkeley Way, Berkeley, CA

94720.

ISSN: 0038-0253 
agents of social control and promotes distrust among the audience. The way the production of entertaining news shapes the content of news can be clarified by looking at the role and use of fear over time across social issues. When fear is the prevailing framework for looking at social issues, then other competing frames and discourses lose out.

When President Franklin Roosevelt said, in the context of the Great Depression, "Let me assert my firm belief that the only thing we have to fear is fear itself," he had not envisioned American news media! Roosevelt cautioned against fear; today fear is embraced and constitutes a major public discourse through which numerous problems and issues are framed. A discourse of fear may be defined as the pervasive communication, symbolic awareness, and expectation that danger and risk are a central feature of the effective environment, or the physical and symbolic environment as people define and experience it in everyday life (Pfuhl and Henry 1993, p. 53). We report on the expanded use of fear in news reports and reflect on its significance for social order.

The prevalence of fear in public discourse can contribute to stances and reactive social policies that promote state control and surveillance. Fear is a key element of creating "the risk society," organized around communication oriented to policing, control, and prevention of risks (Ericson and Haggerty 1997; Staples 1997). A constitutive feature of this emerging order is a blanket reminder of fear. "Fear ends up proving itself, as new risk communication and management systems proliferate" (Ericson and Haggerty 1997, p. 6). While fear is commonly associated with crime, we suggest that fear provides a discursive framework of expectation and meaning within which crime and related "problems" are expressed. Media practices and major news sources (e.g., law enforcement agencies) have cooperatively produced an organizational "machine," fueled by entertainment and selective use of news sources, that simultaneously connects people to their effective environments even as it generates entertainmentoriented profits (Altheide 1997). As one law enforcement official stated about Arizona's televised "crime stoppers" dramatizations, "If you can have a little entertainment and get your man, too, that's great." This discourse resonates through public information and is becoming a part of what a mass society holds in common: We increasingly share understandings about what to fear and how to avoid it. The consequences are felt in numerous ways but particularly in accelerated negative perceptions about public order (e.g., the streets are not safe, strangers are dangerous, the state must provide more control and surveillance). In commenting on everyday life features of mass society, Stanford M. Lyman (1997, p. 294) observes, "Such a fearful disunity undermines the general conditions of trust and order, encouraging intrigues, deceptions and interactions that are strategic rather than spontaneous."

Kenneth F. Ferraro's (1995, p. 121) important work on the fear of crime did not investigate the role of the mass media in public perception of crime and its impact on lives, although he acknowledged that such a study should be conducted: "Beyond the crime rates considered in this research, it would be intriguing for future research to also integrate other ecological variables which may influence fear of crime." Moreover, he wrote, "Added attention to media effects may also be a propitious avenue of research ... it may be useful to give added attention to media effects. Specifically, how do media portrayals and media exposure affect the risk interpretation process? These questions appear worthy of further investigation" (p. 124).

We offer a "mapping" and tracking of fear in The Arizona Republic for 19871996. Our conceptual framework and methodological approach for working with relatively new information bases tracks the rise of fear in selected news media in 
order to demonstrate its expanded use, on the one hand, and to show how a discourse of fear moves across topics over time, on the other hand. "Mapping" refers to where the word and related references to fear occur throughout news reports. "Tracking" discourse involves locating changes in usage, particularly with different topics and issues, over time. The focus is on the term fear, but we are also interested in where it appears, with what meaning, and the themes derived from it. Fear is salient when we apply it to a situation as a relevant meaning. It involves an interaction between an individual and a situation, but it can drastically alter how we deal with that situation and, ultimately, the nature of the situation itself. Indeed, fear may be most important when it is implied as part of a general framework through which events are cast. When fear is used in this way, it becomes a matter of discourse (van Dijk 1988). As an institutional construction of knowledge that is reflexive of "territories, material objects, people, rules, formats, and technologies," the discourse stands for its own foundation and interpretive framework (Ericson and Haggerty 1997, p. 84). This is accomplished through the use of media logic, formats, and frames that shape mass media content (cf. Altheide and Snow 1991; Couch 1984; McLuhan 1960).

We examine recent coverage involving fear in several U.S. newspapers over a several year period for which appropriate information bases are available (1987-1996) but focus mainly on The Arizona Republic (AR). Following an overview of theoretical issues about mass media, popular culture, and fear, we will present materials about the coverage of fear in the AR and some other newspapers. Analysis of some major themes of "fear coverage" will precede a concluding discussion about the implications of a shifting use and expansion of fear in news media.

\section{A Perspective on Fear}

Conceptually, we want to put fear in the contexts of popular culture and mass communication as well as social control and surveillance. Our approach to fear emphasizes its use and place in culture, as indicated by cultural documents such as news reports, the topics and issues with which it is aligned (e.g., crime), and the social effects on decision-makers and other audiences.

While fear is different from specific topics with which it is associated (e.g., crime), we suggest that the expanded and pervasive features of the word "fear" across news sections illustrates a more profound acceptance of fear into everyday discourse which transcends specific topics. Fear is more expansive and pervasive than crime, although the former can clearly include the latter. The rise of "a discourse of fear" is due to its taken-for-granted relevance as an appropriate feature of the effective environment.

Our analysis of fear in the news media crosses several theoretical perspectives including symbolic interactionism, structuralism, and cultural studies. Symbolic interaction suggests that the impact of any message is its contribution to the actor's definition of the situation. From this perspective, the ultimate meaning of any text turns on an actor's interpretation of cultural materials such as news reports (Crane 1992; Maines and Couch 1988; Snow 1983). However, the process and consequences of social definitions extend well beyond "face-to-face" interaction to include the interstices where major decisions are made that shape the contexts of meaning in which day-to-day

decisions are made. Peter Hall's (1997, p. 405) analysis of meta-power is central to any discussion of the impact of mass-mediated discourse on social life: "Meta-power refers to altering the type of game actors play; it refers to changing the distribution of resources of the conditions governing 
interaction." Structuralism, while not completely disinterested in the situation at hand, stresses the cultural contexts of messages, suggesting that the most meaningful communication resonates with deeply held and taken-for-granted meanings and relationships between a symbolic signifer and its referent, or the signified (Eco 1979; Fiske and Hartley 1987; Manning and Cullum-Swan 1994). Cultural studies, drawing on a Marxist view of the production of reality, draw attention to the essential role of mass-mediated messages in sustaining the status quo, including the interests and perspectives of media managers and the interests they serve, which often are at odds with the everyday life experiences of audiences who use this popular culture content (Hall 1977; Kellner 1995; KiddHewitt and Osborne 1995).

An impressive literature on popular culture and fear in the United States, particularly concerning crime, suggests multiple effects (Warr 1980, 1983, 1985, 1987, 1990, 1992), including the rise of "cultural criminology," (Ferrell and Sanders 1995) and "perceptual criminology," or the notion that "many of the problems associated with crime, including fear, are independent of actual victimization . . . because it may lead to decreased social integration, outmigration, restriction of activities, added security costs, and avoidance behaviors" (Ferraro 1995, p. 3). As Mark Warr (1985, p. 283) notes: "And like criminal victimization itself, the consequences of fear are real, measurable, and potentially severe, $\sim$ both at an individual and social level." From the standpoint of media content as "cause," researchers ask whether news reports can "cause" or "lead" people to focus on and fear crime, including the extent to which relevant values and perspectives may be "cultivated" (Gerbner, Gross, Morgan, Signorelli, and Jackson-Beeck 1978). From this perspective, the mass media play a large role in shaping public agendas by influencing what people think about (Shaw and McCombs 1977). The impact of mass media emphases on fear has been examined in France (Robert 1985; Valverde 1995), Finland (Aro, Henriksson, and Lonnqvist 1995), Germany (Taschler-Pollacek and Lukesch 1990), and Switzerland (Killias 1983; Soubiran 1983).

Communication and "media formats" enable us to recognize various frames that give a general definition of what is before us. Studies of media forms and formats have complemented findings from studies of media content, while also giving them a conceptual foundation in the practices of media agents. Seeking to clarify the process by which media messages of violence and fear are presented, this approach essentially asks how events and issues are packaged and presented to audience members who may interpret the messages in a variety of ways. The focus on the processes, practices, and perspectives of newsworkers has clarified how an organized production process shapes news reports, as well as other entertainment-oriented programs (Altheide 1976; Fishman 1980; Gitlin 1980; Tuchman 1978).

Frame, theme, and discourse are also related to communication formats that, in the case of mass media, refer to the selection, organization, and presentation of information. (Altheide 1996, p. 28). Formats pertain to the underlying organization and assumptions of time (temporal flow, rhythm), space (place and visual editing), and manner (style) of experience (Snow 1983). Formats basically are what make our "familiar experiences" "familiar" and recognizable as one thing rather than another so that we can quickly tell the difference between, say, a TV newscast, a sitcom, a talk show.

Frames focus on what will be discussed, how it will be discussed, and above all, how it will not be discussed. (Altheide 1976; Berg 1989; Epstein 1973; Fishman 1980; Zhondang and Kosicki 1993). Frames are like the border around a picture that separates it from the wall, and from other possibilities. An example is treating illegal drug use as a "public health issue" as opposed to a 
"criminal justice issue." These are two different frames that entail a way of discussing the problem and the kind of discourse that will follow. Themes are more basically tied to the format used by journalists who have a short time to "tell a story" that the audience can "recognize' "that they have probably heard before," and moreover, to get specific information from sources that can be tied to this (Iyengar 1991).

The "problem frame" is an important innovation to satisfy the entertainment dimension of news. It is an organizational solution to a practical problem: How can we make real problems seem interesting? Or, more to the practical side of news, how can we produce reports compatible with entertainment formats? The mass media and especially the news business contributed to the emergence of a highly rationalized "problem frame" which in turn generates reports about "fear" (Altheide 1997). The problem frame is a secular alternative to the morality play. Its characteristics include narrative structure, universal moral meanings, specific time and place, and an unambiguous focus on disorder that is culturally resonant.

The problem frame combines the universal and nonsituational logic and moral meanings of a morality play (Unsworth 1995) with the temporal and spatial parameters of a news report-something happened involving an actual person in an actual location. Unlike a morality play in which the characters are abstractions facing death and damnation, news reports focus on "actual" people and events, packaging the entire narrative as "realistic." Complex and often ambiguous events and concerns are symbolically mined for moral truths and understandings presumed to be held by the audience, while the repeated presentations of similar scenarios "teaches" the audience about the nature and causes of "disorder" (Ericson, Baranek, and Chan, 1989).

One attempt to synthesize these major views within a coherent framework is "an ecology of communication," or the emerging relationship between information technology, communication formats, and social activities (Aitheide 1994, 1995). From this vantage point, the production and interpretation of messages is organized around technological, communication, economic, and entertainment considerations. The line between consumers and producers becomes blurred as mass-mediated information joins the production and packaging of messages to the audience's knowledge of products and issues. The effect is more pronounced when media reports are reproduced in other messages. This process has been described by Peter Manning (1998, p. 261) as a "media loop": "When an image is shown in another context, reframed by the media. .. Media images are constantly recycled, reproduced in a new context, and reexperienced."

Mass mediated experiences, events and issues are particularly salient for audiences lacking direct, personal experience with the problem. Indeed, many observers have wondered how it is possible for a comparatively healthy and safe population to perceive themselves to be so at risk. Research on media violence suggests that violent content can lead viewers to perceive life as "scary," dangerous and fearful (Gerbner and Gross 1976; Signorelli and Gerbner 1988; Signorelli, Gerbner, and Morgan 1995). Linda Heath and Kevin Gilbert (1996, p. 371) note in a review of more recent research on mass media's relevance to crime: "Because the media often distort crime by overrepresenting more severe, intentional, and gruesome incidents, the public overestimates its frequency and often misperceives reality." Broader effects of mass media presentations include the ways in which public perceptions of problems and issues (the texts they construct from experience) incorporate definitions, scenarios and language from news reports (Altheide and Snow 1991; Bennett 1988; Comstock 1980; DeFleur and Ball-Rokeach 1982, p. 244; Ericson 1995; Ferraro 1995; Snow 1983). Indeed, how the mass media report risk suggests that journalists need to be more conscientious and informed in their accounts (Willis and Okunade 1997). 
While crime and violence are part of the "fear story," there is more to it. For example, the constant coupling of crime and other aspects of urban living with fear have produced a unique perspective about our effective environment. While crime is certainly something to be concerned about, as is any potentially dangerous situation, the danger per se does not make one fearful, just cautious. Fear is not a thing but a characteristic attributed by someone (e.g., a journalist). Often associated as an attitude pertaining to danger, fear is multifaceted in its actual use in popular culture and especially the news media.

Examining the impact of subjects' perceptions of crime on their orientations and behavior, Ferraro's (1995) research on "fear of crime" distinguishes between perceiving a "risk" and being "fearful": "Fear of crime is an emotional response of dread or anxiety to crime or symbols that a person associates with crime ... To produce a fear reaction in humans, a recognition of a situation as possessing at least potential danger real or imagined, is necessary. This conception of potential danger is what we may call perceived risk and is clearly defined by the actor in association with others." An actor has options. "Fear is only one of several reactions to judgments of potentially high risk in a situation. Others may include constrained behavior, community or political activism, compensatory defensive actions, and avoidance behaviors including relocation. Perceived risk and the possible reactions to it are viewed as always being developed in an environmental context replete with socially constructed meanings" (Ferraro 1995, p. 12). Ferraro notes that people take precautions in everyday life to avoid situations that are perceived to be potentially risky, but not at the same moment "feared." This distinction is seldom made in news reports, which tend to use "fear." An example of a rare report that seeks to "uncouple" risk from fear focused on fire. The following excerpts are offered to illustrate what is seldom seen when it comes to crime $(A R$, November 8, 1994, $\mathrm{Dl})$.

Take A Positive Approach: Teach Kids to Respect Fire, Not Fear It

Look to Child Life for answers to your child-rearing questions. Call the hotline at 1-800-827-1092 with any questions or tips you might have. Or write to Beverly Mills, Child Life, 2212 The Circle, Raleigh, NC 27608.

QUESTION: Our 3-year-old grandson has become very curious about cigarette lighters, candles and other fire. We wonder what would be the best way to instill the danger of fire so he won't get into trouble. Karen Dennis, Phoenix

ANSWER: Especially with young children, take a positive approach to teach respect for fire rather than try to instill fear, parents and fire safety experts advise. And now is the time to childproof your home if you haven't already.

Lots of parents who called Child Life say once fire is no longer such a mystery, children tend to lose interest.

The report recommended particular methods for teaching children about the hazards of fire and offered tips to parents for acquainting children with potential dangers, and how to avoid them. The focus was on education and proactive action. This is a rare treatment of fear.

\section{Perceptions of Fear}

Fear has become a staple of popular culture, ranging from fun to dread. Americans trade on fear. News agencies report it, produce entertainment messages (other than news), and 
promote it; police and other formal agencies of social control market it. And audiences watch it, read it, and according to numerous mass entertainment spokespersons, demand it (Clover 1997).

Numerous opinion polls document Americans' fear. For example, Americans think they are subjected to more risk today than their parents were twenty years ago. According to a study reported in the Los Angeles Times (September 11, 1994, p. Al), 78 percent of Americans feel they are subject to more risk, 6 percent feel they are subject to less risk, 14 percent to about the same risk, and 2 percent indicated that they were not sure.

While most of the concerns about fear have been associated with crime, it is apparent that fear has increased despite fluctuations in the crime rate. According to the FBI's Uniform Crime Reports, the national violent crime rate began a slow descent in 1992. Even the juvenile arrest rate, which rose 69 percent between 1987 and 1994, began to decline in 1995-1996. Still, as sociologist Dane Archer of the University of California, Santa Cruz, put it: "There is the actual crime rate, and the fear of crime rate" (USA Today, December 9, 1994, p. 4A). Generally, national public opinion surveys show that the public's fear of crime continues to increase despite the declining crime rate. Many polls declare that crime is the number one concern of many Americans, such as in Detroit in 1996 or Phoenix in 1995. In 1982, only 16 percent of Americans responded that fear of crime and violence was a very serious problem for them, while another 25 percent called it a serious problem. By 1995, nearly one-third of Americans told pollsters that they considered crime a problem for them personally. More than 70 percent felt crime was a major problem for people over sixty-five years of age.

When politicians anticipate public response to an issue, they react: President Bill Clinton, in his 1994 State of the Union address, described the national landscape as "shattered by crime" and placed fighting crime at the top of his political agenda. In 1997, Senate Majority Leader, Trent Lott, announced that fighting the twin scourges of crime and drugs would be a top priority of the 105th Congress. This announcement was in response to opinion polls showing consistently that the fear of falling victim to random violence continues to weigh heavily on the minds of millions of Americans.

Fear of crime in the United States has led a substantial number of people to change their habits and life-styles including limiting such activities as places and times they will go shopping, places and times they will work, and where they will go alone. Many individuals have purchased weapons, installed home security systems, changed vacation and travel plans, refrained from wearing jewelry in public, dressed more conservatively, and now keep their car windows rolled up and doors locked at all times. Fear of crime is consistently given as a response when people are asked "In what ways has a decline in values directly affected their quality of life?" Of those who say they are having a very difficult or somewhat difficult time living in harmony with the values they hold, 6 percent give fear of crime/violence as the reason.

Even though in 1996 many polls found that people considered crime to be a city problem rather than a problem of their neighborhood, spending for private security has risen substantially. It is 73 percent higher than spending for public law enforcement. According to a National Institute of Justice study, 1.6 million private security officers outnumber law enforcement officers nearly 3 to 1 (USA Today, December 9, 1994, p. 4A). The study also estimates that by the year 2000 , more than $\$ 100$ billion will be spent on private security annually. 
Numerous opinion polls indicate that Arizonans join citizens throughout the Unite States (Ferraro 1995) in regarding crime as a major problem. In 1991, 3 percent of Arizonans regarded crime as a major problem. About half of those polled expressed this view in 1994, but by 1997 more than 80 percent felt this way. A poll by the Morrison Institute for Public Policy at Arizona State University in spring, 1997, found that 33 percent of Arizonans regard crime as a severe problem, with another 53 percent viewing it as a problem. Forty-six percent indicated that they perceive gangs as a major problem, and more tha half believe that crime has increased during the past year (AR, September 14, 1997' Indeed, public safety and crime was ranked as the second most important item in the region, behind only education, but ahead of families and youth issues, health care, economy, and the environment.

Researchers have argued for decades that such concerns are connected to the mass media coverage of news as well as entertainment (Comstock 1980; MacKuen and Coombs 1981; Surette 1998). An abundant body of research and theory suggests that the news media contribute to public agendas, official and political rhetoric, and public perceptions of social problems, as well as preferences for certain solutions (Graber 1984; Shaw an McCombs 1977; Surette 1998). For many people, the mass media in general, and the news media in particular, are a "window" on the world. How the public views issues and problems is related to the mass media, although researchers disagree about the nature of this relationship (Gerbner and Gross 1976; Gunter 1987; Hirsch 1980; Katz 1987; Schlesinger, Tumber, and Murdock 1991; Skogan and Maxfield 1981; Sparks 1992; Zillman and Wakshlag 1987). This is particularly apparent when fear is associated with popular topics like crime, violence, drugs, and gangs, which have become staples of news reports as well as in entertainment media. What audiences perceive as a "crime problem" is a feature of popular culture and an ecology of communication (Bailey and Hale 1998; Ferrell and Sanders 1995). Mapping how fear has become associated with different topics over time can clarify how the mass media and popular culture influence public perceptions of danger and risk. We turn to a discussion of mass media messages about fear in the context of popular culture.

News reports are the major source for most citizens' information about crime and related issues, as well as opinion results. The 1997 survey results reflect many experiences by the public, including numerous news reports during our period of study. Consider an example, "Burning Issue for Arizonans: Fear of Crime" (May 22, 1994): Carina Koshinski of Glendale remembers the day her son walked into a bathroom at Independence High School and found another student loading his gun.

\footnotetext{
"The thing that worries me the most is that he wasn't shocked," she said. "I hate to see it be so blasé for him.

"He said it happens all the time, and you just stay away from it."

Koshinski, a mother of five, is not alone in worrying that the threat of violent crime has become part of everyday life.

Arizonans worry about crime to the exclusion of almost every other issue, according to a poll conducted this month for The Arizona Republic and KSAZ-TV (Channel 10). The poll was done to find out what voters have on their minds as the fall elections approach...

For candidates, the message is clear: Arizonans want solutions to violence, and they will be looking to the candidates for public office to give them answers.
} 
As Koshinski said, "Things have changed to where if a car pulls up and (someone) asks you for directions, you don't know if they're going to shoot you:'

Nearly everyone — 95 percent of those polled — believes that crime and gangs are serious problems in Arizona.

The fear is not only broad, it runs deep: 83 percent strongly believe crime is a serious problem, and 79 percent have strong concerns about gangs...

Why the dramatic turnaround?

"Crime is a lot more visible than it was three years ago," said Ellen Jacobs, research manager for Phoenix Newspapers Inc., publisher of The Arizona Republic." (emphasis added).

\section{TRACKING FEAR}

\section{Materials and Method}

Methodologically, we build on the conceptual points noted above. Our aim is to understand the themes and discourse that surround fear and make it salient for the presentation and discussion of certain issues to audiences. These queries hinge on issues about change, but systematic study of news content and themes over time can benefit from the recent development of information bases. Future work will examine the place of fear in newspapers, magazines, and television, particularly news. Notwithstanding the Vanderbilt University Television News Index and Archive, systematic study of TV news of the kind we describe below will be very difficult until visual information bases become as accessible.

The major information source for this project was newspaper transcripts from The Arizona Republic (AR). (Several other major dailies such as Los Angeles Times, and New York limes, were used for heuristic comparisons during the preliminary analysis.) Most materials were obtained from the on-line information base LEXIS/NEXIS (LN), the most comprehensive legal, news, government document, and public information source available. $\mathrm{LN}$ is an interactive information base that permits searching for key words, delimited in numerous ways, e.g., by segments (sections of the newspaper), date, etc. Issues of the $A R$ were available in LN from 1993. Issues of the $A R$ prior to 1993 were obtained from the CD-ROM information bases ARIZONA REPUBLIC and NEWSBANK. These sources provided some comparative materials that were adequate for tracking some changes over time, although the majority of the qualitative analysis focused on reports in 1994-1996.

The search process is made possible by sophisticated information bases, but they are not comparable in all respects, and some newspapers involve multiple counts, and so on. Two major search decisions were made. One was to search for fear in the segment "body," rather than the entire text. This meant that articles that only had "fear" in the headline may be excluded. However, these would be picked up in subsequent searches for "headlines." Second, searches were conducted in all text (and not just the segment "body") for fear within/a number of words or topics in order to include all relevant materials. Third, articles were sought across sections on a dozen topics which have been useful in earlier analyses of media formats and emphases (e.g., violence, crime, community, neighborhood, schools, drugs, gangs, retribution, children, terrorism, environment, and immigrants.) A theoretical sample of nearly two hundred articles from The Arizona Republic was analyzed, along with samples from several other media including the Los Angeles Times, New York Times, and ABC News. 
Data collection and analysis were conducted using an approach described elsewhere as "tracking discourse" (Altheide 1996). This is primarily a qualitative document analysis approach that relies on analysis of numerous documents in order to become familiar with formats and emphases, while suggesting topics and themes. Initial manifest coding of fear and related topics then incorporated emergent coding and theoretical sampling in order to monitor changes in coverage and emphasis over time and across topics. On the one hand, this approach makes it possible to answer such questions as "is fear associated with different topics over time?" On the other hand, the latent and emergent approach is very conducive to "problem frame" analysis noted above, as well as systematic comparison of thematic emphases.

Involving twelve steps, tracking discourse entails initial familiarity with a sample of relevant documents before drafting a protocol, which is then checked for reliability and validity with additional documents. A protocol was constructed to obtain data about date, location, author, format, topic, sources, theme, emphasis, and grammatical use of fear (as noun, verb, adverb). However, materials may also be enumerated and charted. Once collected, the materials were placed in an information base and analyzed qualitatively using Word 7 and NUDIST, a qualitative data analysis program, as well as quantitatively with a spreadsheet, Excel. Accordingly, the following sections will present both enumerative and qualitative aspects of the coverage of fear in the $A R$.

\section{The Arizona Republic in Perspective}

A basic question for this project concerns how much coverage the $A R$ has given to "fear" over a several year period. We discuss this here as both a conceptual and methodological issue in order to locate this case study within a larger population of newspapers. Figure 1 provides a basic description of fear in headlines and text in the $A R$ from 1987-1996. The use of fear about doubled in both categories: "fear" was in headlines 123 times in 1987 and 232 times in 1996; it was in text 1,379 times in 1987 and 2,209 times in 1996. In order to gain some appreciation for the relative position of the $A R$ in the use of fear in headlines and text of news reports, comparisons were made with ten major newspapers in the United States (The Atlanta Journal and Constitution [ATLJNL], The Boston Globe [BGLOBE], The Chicago Tribune [CTRIB], Dallas Morning News EDALNWSI, Kansas City Star [KCSTAR], Los Angeles Times [LAT], New York Times [NYT], Seattle limes [SEATTM], St. Petersburg Times [STPETE], Washington Post [WPOST]).

There are several points to stress. Fear is no stranger to major metropolitan newspapers in the United States, although the newspapers vary considerably in their use of fear. The use of fear in headlines and text increased from 30 to 150 percent for most newspapers analyzed over a 7-10 year period, with the peak year in 1994 (data not provided). Many of these increases were associated with more emphases on crime reporting (data not presented). Figures 2 and 3 present data for 1994-1996, which shows that the $A R$ is similar to these other newspapers regarding the use of the term fear in text of reports as well as headlines, which stress fear even more. Figure 4 shows that between 1994-96, the $A R$ ranked eighth (eleven is high) among these papers in fear in headlines and fifth with fear in the text. It was also one of the leaders (seventh - there were several "ties") with fear in headlines as a percentage of reports with fear in the text. This indicates the relative significance of fear for a newspaper when it is used. Thus, the Kansas City Star, compared to the other papers in our study, uses fear relatively little in either text or headlines. However, when 


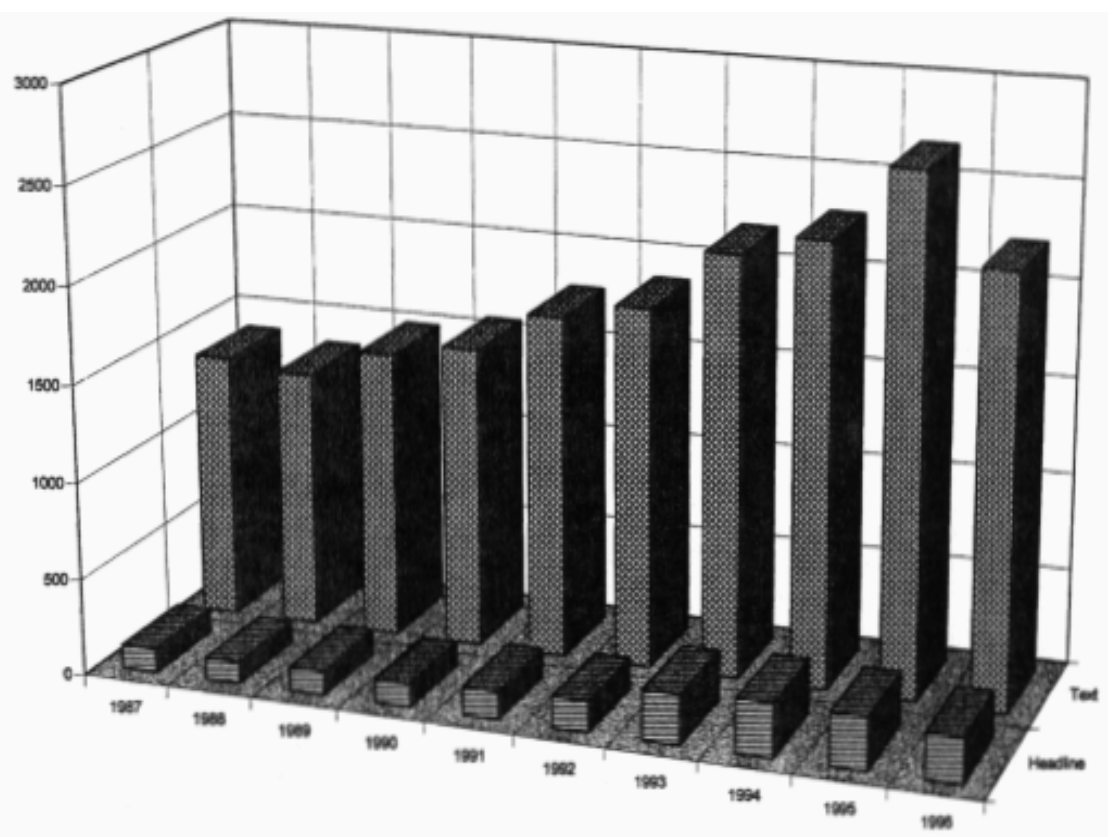

FIGURE 1. FEAR IN TEXT AND HEADLINES, ARIZONA REPUBLIC, 1987-1996

fear is used in a report, it is more likely than the other papers to be used in a headline. It should also be noted that the "prestige newspapers" (the Washington Post and New York Times) used fear in headlines comparatively less in terms of the total number of stories they presented in which fear was mentioned.

These data are important to understand part of the process for gathering reports that appear in the $A R$ since newspapers share not only "wire service" reports (e.g., reports with an Associated Press byline), but they also share information. Thus, what appears in the Los Angeles Times or the Chicago Tribune may also show up in $A R$. Further, it is widely understood that newspapers, like other media outlets, share perspectives on news and look to each other for guidelines about formats, topics, and emphases. And reporters and editors move from one locale to another. Not surprisingly, then, reports about certain topics (e.g., "carjackings") may start in one part of the country and find their way into news coverage in other regions and cities, even if the particular "crime" has not drastically increased.

\section{Arizona Republic Sections and Formats}

The news is a business. It is commonplace that news is a commodity. Newspaper organizations earn revenue in two basic ways: selling an audience with certain demographics to advertisers, who purchase space for ads to reach that audience and selling the newspaper to customers. While the relative amounts of these two sources of revenue vary from one 


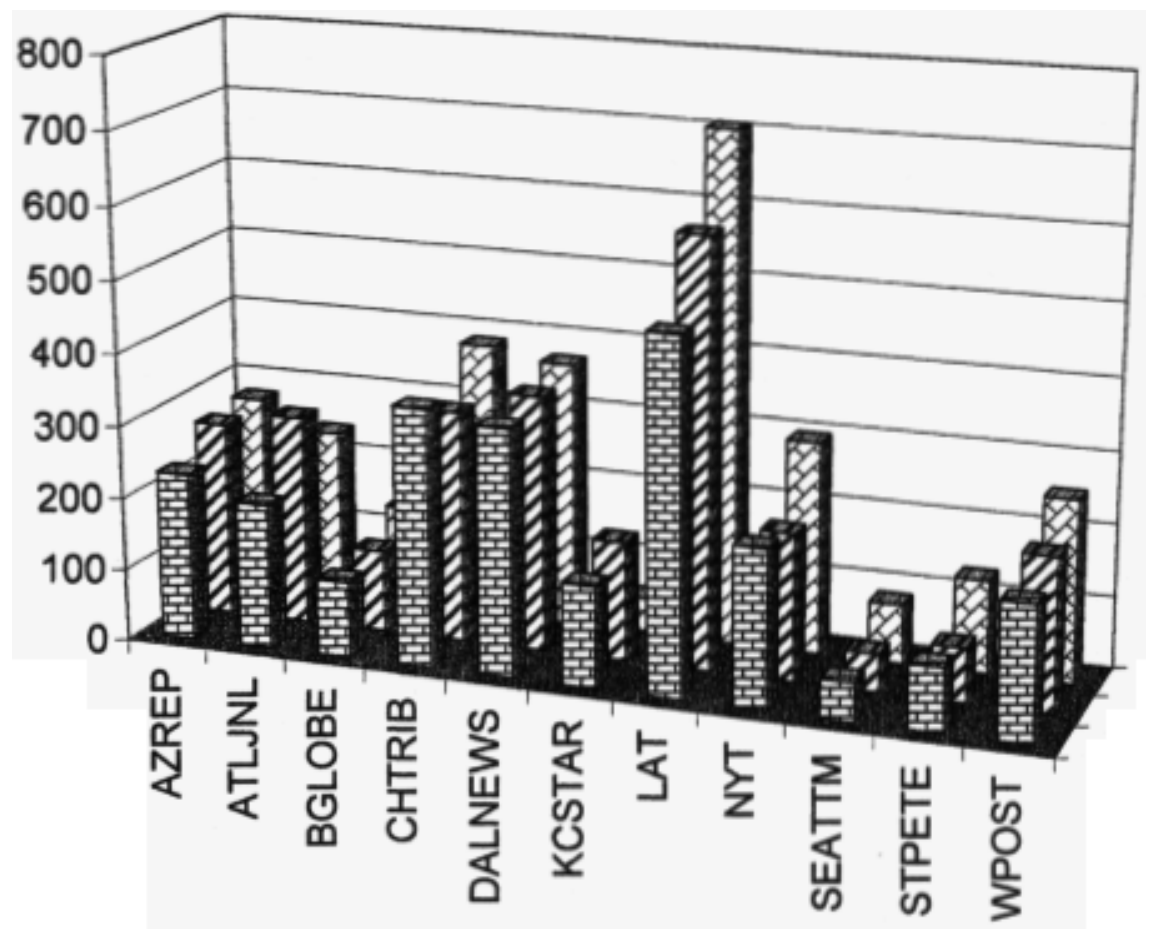

FIGURE 2. FEAR IN HEADLINES, 1994-1996

newspaper to the other, the former surpasses the latter. Nevertheless, audiences are important in order to attract the lucrative advertisers.

The $A R$ enjoys a position not unlike dailies in many American cities: there is little competition for readership. For years, Phoenix Newspapers owned and operated two papers, the $A R$ and the Phoenix Gazette, but the latter has now been incorporated into the former, leaving one major newspaper in Phoenix, although there are some other options, mainly in the East Valley (e.g., Tribune Newspapers).

As a business, the $A R$, like most major U.S. dailies, must adjust to a changing audience that is constantly being cajoled and approached by a massive popular culture industry, particularly television, which adds a visual dimension to an entertainment format that displays emotion (Altheide and Snow 1991). Indeed, TV news has been credited with declining newspaper readership during the last twenty years. This requires that newspapers, in turn, attend to audience interests and perspectives. Thus, newspapers have become more entertainment oriented, and particularly, more attuned to lifestyle preferences of readers. Thus, major format changes have taken place in the $A R$ and most other U.S. dailies.

The $A R$ has numerous sections marked off by substantive focus, such as "hard news," "features," or less timely news, comics, sports, business, and so on. Historically, fear has been associated with the "hard news" sections. Tracking fear across various sections over time articulates fear as discourse as a more general orientation to events and topics beyond 


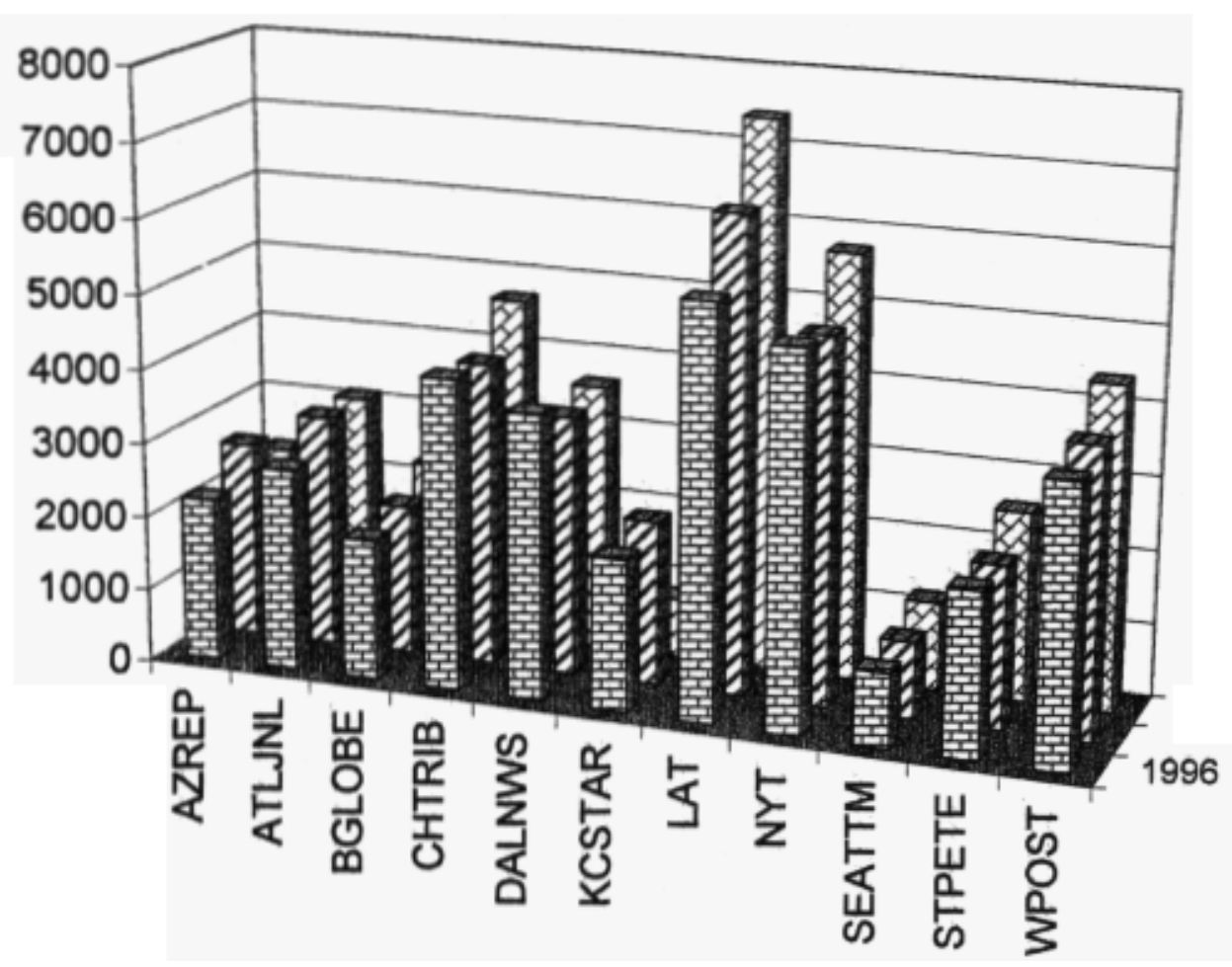

FIGURE 3. FEAR IN TEXT, 1994-1996

specific content. Like most metropolitan dailies, the $A R$ is international and local news coverage has decreased in favor of providing materials deemed worthwhile by market research, such as personal finance, computers, lifestyle, business, and of course an expanded sports section.

We examined how news reports featuring fear were arrayed across some of the major sections. (Figure 5). Fear is more widely distributed across the various sections of the newspaper than we imagined. One finding is the stability of fear over the three-year period under investigation (1994-1996), as well as across sections of the newspaper. From 1994- 1996, fear was a staple of numerous sections, albeit to varying degrees, in the $A R$. We examined fear in text and headlines in seven sections of the $A R$ (Figure 6): front, valley/ state, sports, business, community (of which there are at least thirteen subsections), life, and editorial. Even in sports, the section touted by some as an "escape from real life," an occasional headline with fear appears! There is surprisingly little variation over time.

Examining Figures 5 and 6 illustrates a general stability of fear in text and headlines, respectively, during this time period. The ratio of fear in the "body" of news reports (or the text) to fear in the headlines varies across the sections, from 7:1 in the front section to $29: 1$ in the editorial/opinion page. The latter discrepancy is partly due to the inclusion of numerous letters (as text only) that often do not have their own headline. The biggest increases in fear in headlines occurred in sports, while the largest increase in fear in text 


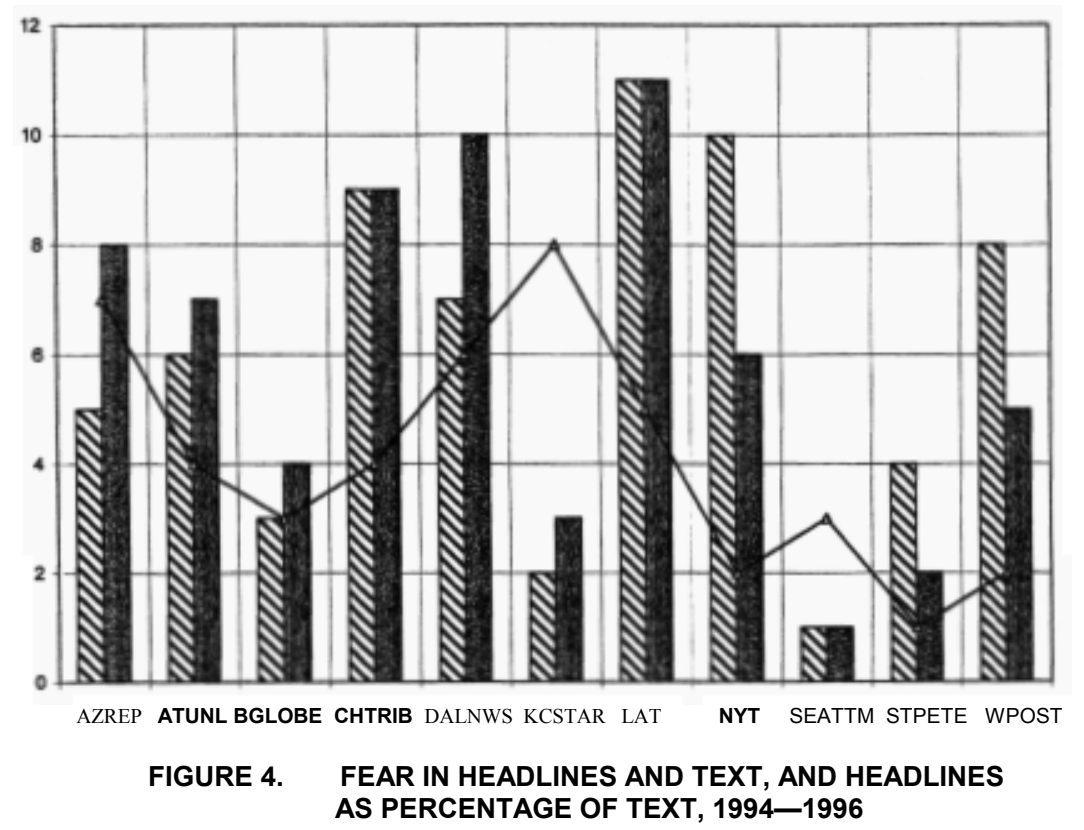

over the three-year period occurred in business. While the largest proportion of reports and headlines featuring fear occur in the "front" section of the $A R$ (for example, 55 percent in 1996) (see Figure 6), it is noteworthy that fear appears throughout the other major sections, particularly editorials, valley/state, and business. This is partly due to the use of fear as a noun, verb, adverb, and adjective. However, fear is also quite common in the editorial section, often in the form of "op ed" pieces. We want to stress the multiple ways in which fear is used by journalists across subject matter.

\section{The Topics of Fear}

The substantive focus of fear also varies widely over time and across topics, Indeed, this i certainly as important as the increased use of fear, since other terms are used more as well The substance of "tracking discourse" is to delineate the nature and extent of this change As noted previously, reports were sought across sections on a dozen topics that have been useful in earlier analyses of media formats and emphases (e.g., violence, crime, community, neighborhood, schools, drugs, gangs, retribution, children, terrorism, environment and immigrants; Altheide 1997). (It is apparent that the use of fear has about doubled during this decade, although other work documents that fear has about tripled in headlines in the Los Angeles Times and in ABC television news reports (Altheide 1997). The intent was to see how the relative association of fear with certain topics may vary over time in order to examine public discourse about topics and important social issues. In order to check comparability with some previous work, we also examined the association of fear with the topics of AIDS, homelessness, and cancer. On an average day, a thorough reader of the $A R$ would read 6-7 reports containing fear, and about one headline a day with the word fear in 


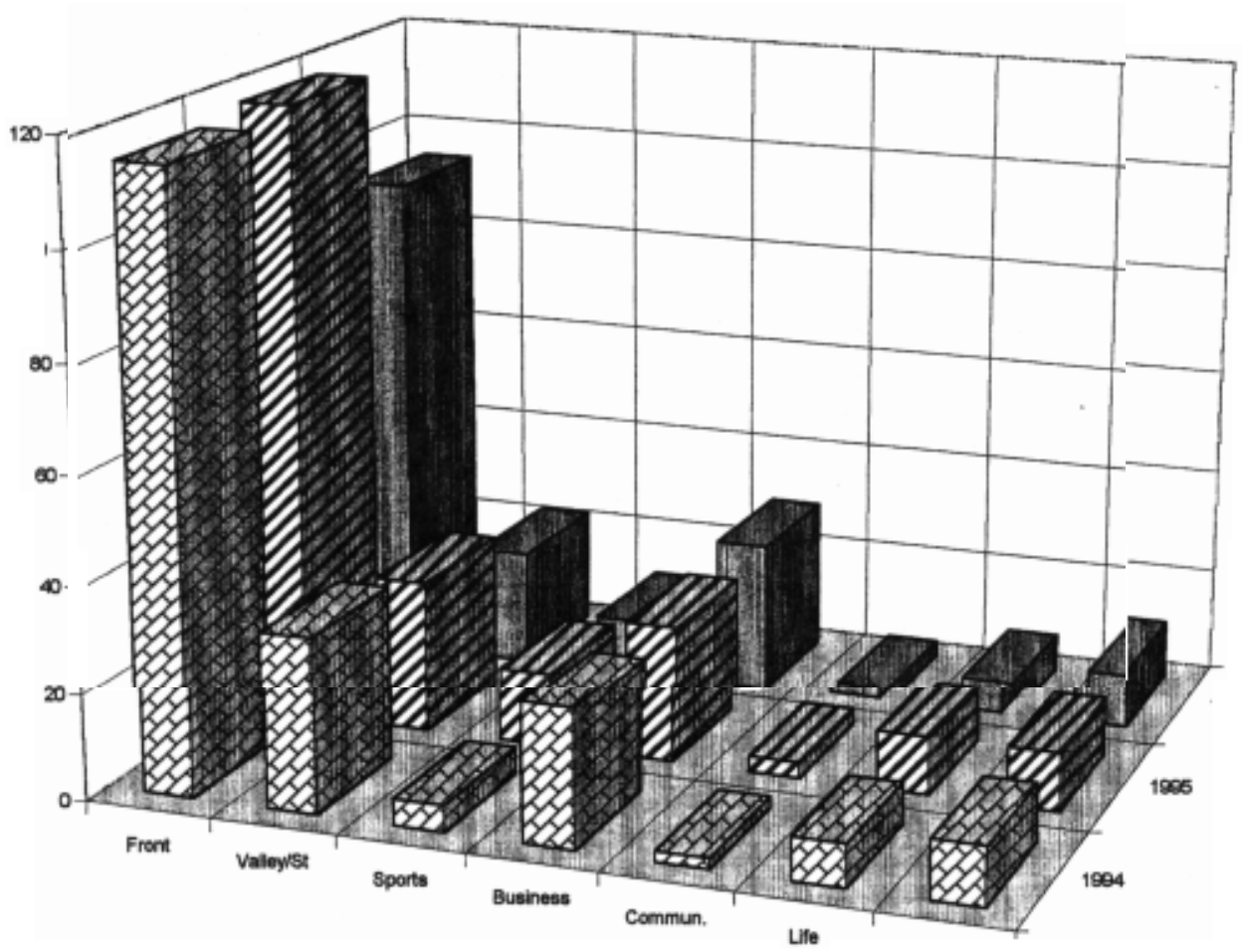

FIGURE 5. FEAR IN HEADLINES BY SECTIONS, ARIZONA REPUBLIC, 1994-1996

it. Over a three-year period, more than 21 percent of these reports associate fear in some with the topics presented in Figure 7.

\section{Explicit and Implicit Fear}

Topics become associated with fear through a process. Problems (and associated terms) a "meaning career' often beginning as something that is deviant or immoral, later becoming more accepted - although not necessarily desirable. This occurs in part through c communication and includes the journalists who write about such topics, as well as sources" which supply them with information and understanding. These sources can id to essentially "own" the meaning of the problem or issue (Surette 1998). We communicate differently about things as they become more familiar because taken-for-granted notions incorporate what is "obvious." For example, when reports routinely stress suffering and mayhem, fear becomes incorporated into the meaning: signifier and signified are essentially joined and taken for granted. In this manner, we argue that a clear indication of public familiarity with a topic, as well as how it has "moved" from one body of "experts" other, is the prevalence of "fear" associated with it. 


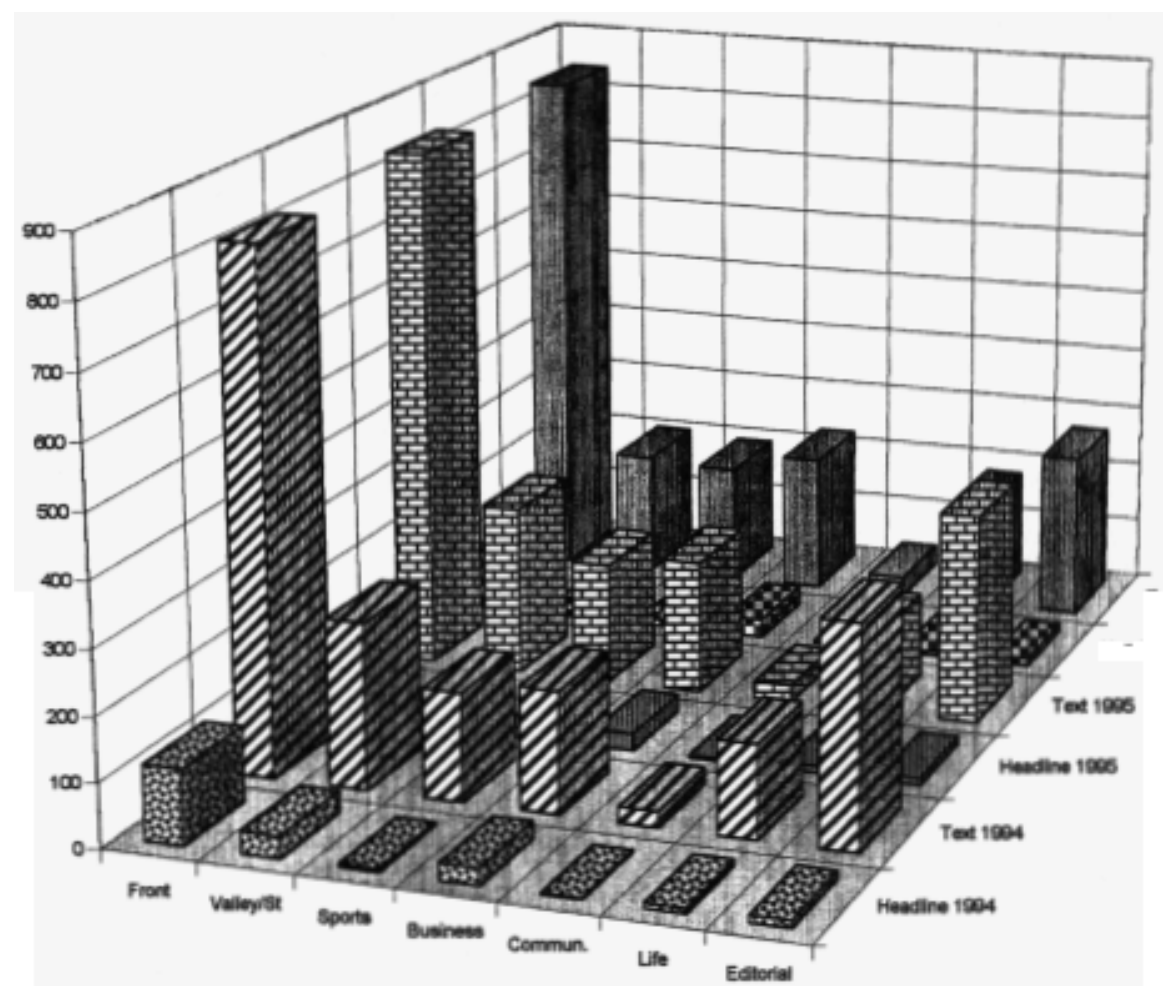

FIGURE 6. FEAR IN TEXT AND HEADLINES BY SECTIONS, ARIZONA REPUBLIC, 1994-1996

One example from previous work is "cancer' a term that seldom appears in conjunction with "fear" in mass media reports (Altheide 1997). This is not because cancer is no longer feared, but, to the contrary, is so overwhelmingly undesired - yet familiar - that it has been recast repeatedly into other discourses, such as medicine, health, and education. This has occurred because the sources for reports about cancer tend not to be police officers or public officials but to be professionals trained in medicine, public health, and education. (However, the "fear" of cancer has been "appropriated" by politicians who use cancer as a metaphor to refer to "crime"!)

To speak metaphorically, fear has "traveled" across all the topics we examined since 1987, although children, crime, and schools have remained in the top three categories. It is apparent that changes occurred in the coverage of selected topics and the way they have come to be associated with fear. As Figure 7 indicates, the association of certain topics with fear expanded with other topics as well, particularly with children and schools. This is common with the mass media across the United States, but the extent of change is noteworthy. For example, in 1987, there were 8 and 7 stories, respectively, of the terms violence and crime occurring within 10 words of fear. By 1996, the association of fear with violence and crime had increased six-fold. Indeed, since 1994 those topical associations of 


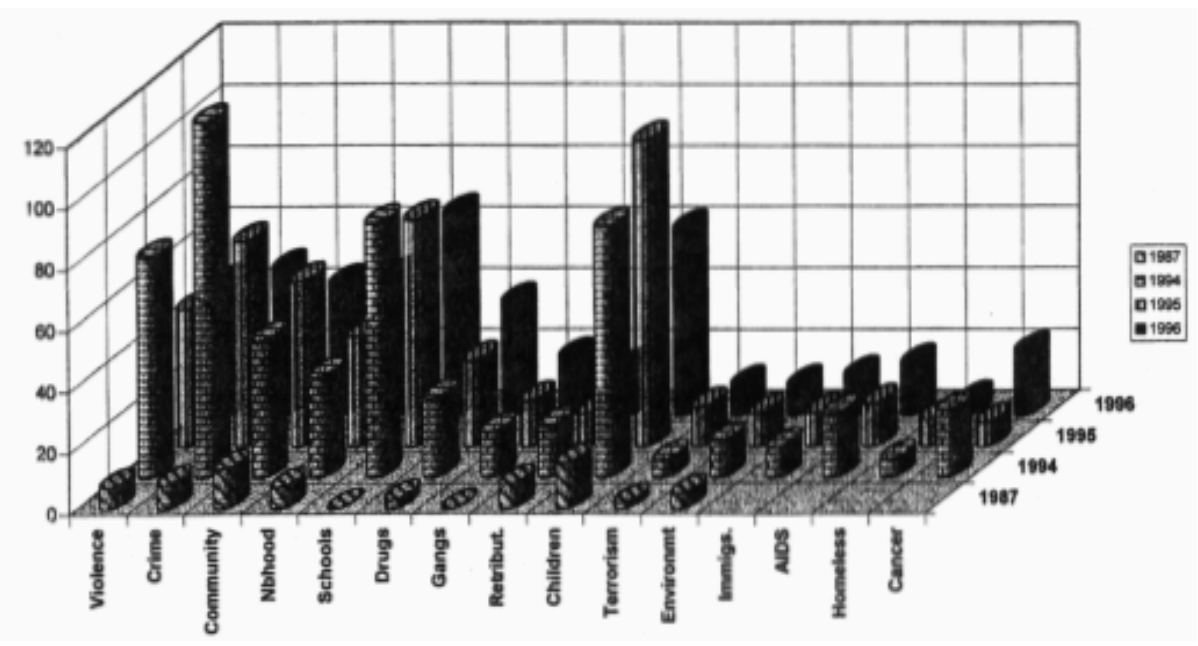

FIGURE 7. FEAR WITHIN 10 WORDS OF TOPICS, ARIZONA REPUBLIC, 1987 AND 1994-1 996

fear with children and schools have exceeded violence, drugs, and gangs. While other work has suggested that people still associate gangs with danger, fear, and undesirability, the connotation of gangs now contains fear and danger, so it is no longer made as explicit.

Fear travels in public discourse as it becomes associated with topics over a period of time. Frames are akin to boundaries and borders; and like border incursions, we are most aware of them when they expand into other "territory" or contexts of meaning. But when the incursion occurs subtly and accompanies well-traveled issues like crime, the adjustment is most likely noticed as a nuance, if at all. Over time, with repeated usage, nuances blend, connotations become denotations, fringes mix with kernels, and we have a different perspective on the world. This is why the distinctions between meaningful borders like children, school, and community are so important. When they are joined with fear, more than a visit is in the works: there is an incursion.

The entertainment format uses children for its invading force. Another way to track the relative changes in associating fear with news coverage of particular topics can be illustrated by focusing on children. Reports about children provide a view into fear as a feature of the problem frame.

Examining numerous articles featuring children and fear shows several things. First, although the public is likely to associate fear with violence, crime and drugs, this research suggests that from 1994-1996 fear was associated with news coverage about children. These "fear" topics do not appear very frequently in headlines with fear, but when they do, crime, children, schools, and community are the most common. These topics "express" fear and have become increasingly associated with it. For example, in 1994, 57 percent of all reports with "fear" included one or more of the following words: children, crime, schools, violence, community, or police (data not provided here). The news media's emphasis of fear with children is consistent with work by Warr (1992) and others on the significance of "third-person" or "altruistic fear"- - the concern for those whom you love 


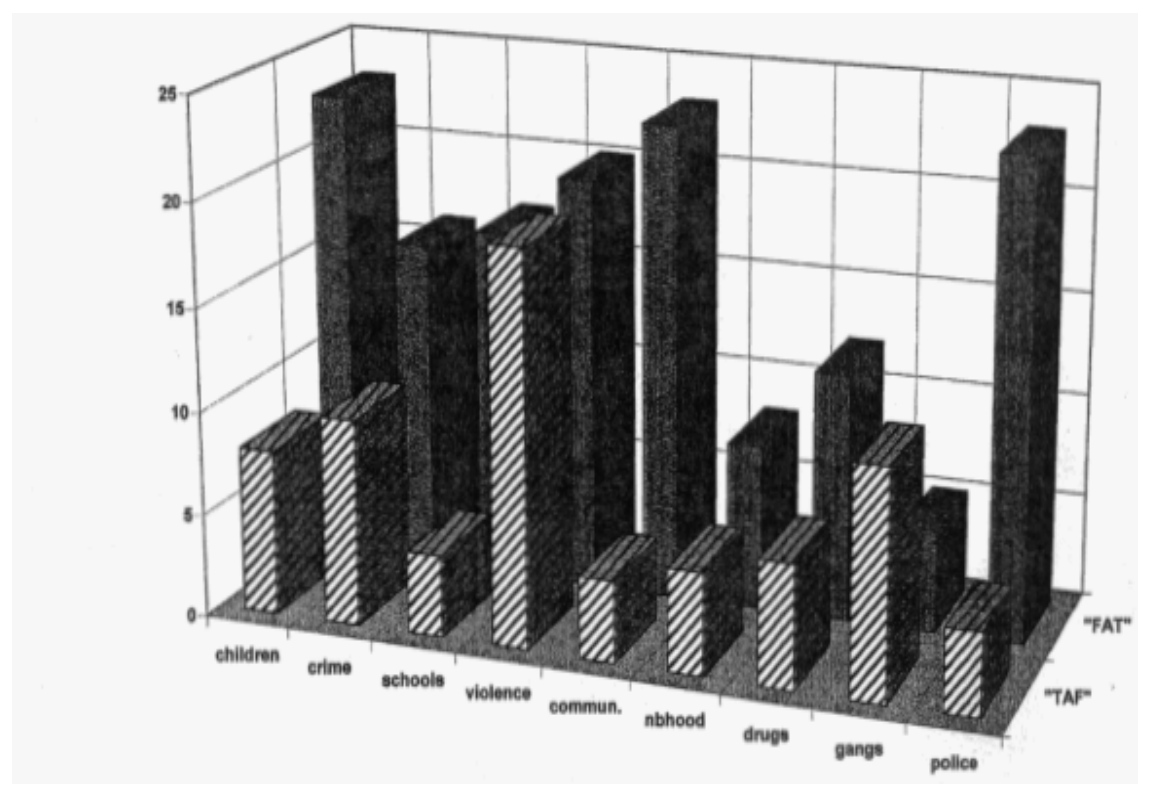

FIGURE 8. FEAR-AS-TOPIC (FAT) VS. TOPIC-AS-FEAR (TAF) BY PERCENTAGE, ARIZONA REPUBLIC, 1994-1996

or are responsible. Specifically, Warr (1992) found that children are the most common object of fear in households. Thus, the news media's emphasis on children is consistent with readers' priorities. Second, when these topics occur in headlines, fear is seldom mentioned in the accompanying text of the articles. When fear is mentioned in the headline and the article, the topic that appears the most frequently is violence (19 percent), followed by gangs and crime. Third, headlines featuring fear are more likely to be associated with certain topics (Fear-as-Topic or FAT) than headlines about topics being associated with fear (Topics-as-Fear or TAF)! Stated differently, when fear occurs in headlines, the most common topics are children, schools, community, and police!

The point we are stressing is that fear is a dominant orientation that is "shown" and "lives" through certain topics. Thus, headlines about children were associated with fear (TAF) in only 8 percent of the reports in 1994. (Figure 8) However, nearly a fourth of all reports with fear in headlines (FAT) referred to children in the body of the text in 1994, 1995, and 1996. Essentially the same magnitude was apparent with community, but also note the position of schools. A comparison of FAT is offered with the Los Angeles Times (LAT) for 19941996 (Figure 9). The similarity in "profiles" is striking in the way fear is associated with certain topics, particularly children, community, schools, and police are prominent "topics" appearing in reports with "fear" in the headlines. (Data further suggest that the Washington Post and New York Times, increased FAT with children, schools, and community over the last two decades.) 


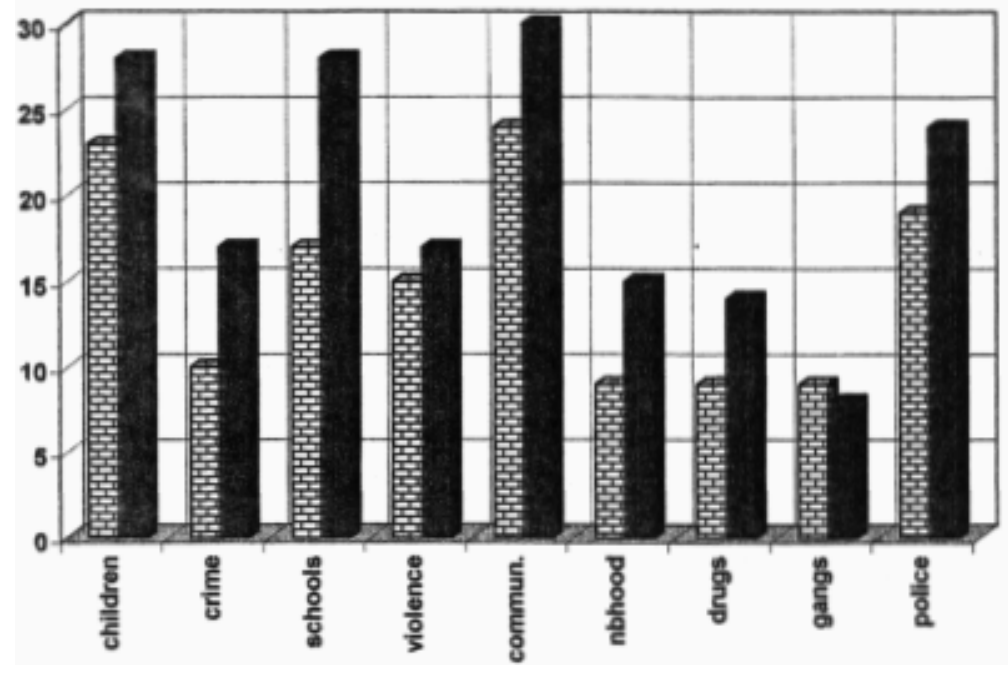

FIGURE 9. HEADLINE OF FEAR AND FOCUS ON TOPIC IN TEXT BY PERCENTAGE, ARIZONA REPUBLIC AND LOS ANGELES TIMES, THREE YEAR AVERAGE, 1994-1996

The argument to this point is that these are not mere words used for a matter of convenience to communicate effectively but have come to be linked to an orientation and course of action implying danger, avoidance, proactive precautions, and threat. These relationships can be illustrated by themes in a sample of articles.

\section{Themes of Fear}

Fear becomes a matter of discourse when it "expands" from being used with a specific referent to use as a pervasive problem and more general orientation. Tracking the usage of fear surrounding "children" illustrates how fear comes to be associated with certain topics and issues as part of a problem frame. Our data suggest that reports involving children and fear changed between 1987 and 1994. As Figure 10 suggests, in 1987, usage of fear can be characterized as localized, momentary, individually experienced, and often urban as opposed to suburban. We suggest that these characteristics mark journalistic reporting outside of the problem frame. For example, "We fear for our children on the streets as they walk to the elementary school," Steichen said (AR, April 27, 1987). The use of the word fear in this instance relies on a first order connotative value related to a specific issue at a specific time.

Accounts in the $A R$ in the later years of our study can be characterized as moving to a problem frame ("fear frame") consistent with fear as a discourse, characterized by a more generalized, pervasive, unfocused standpoint. For example, "Hers was the name that shattered the innocence and security of smalltown life and glued it back together with fear. Nickie Fater. Loving wife. Dedicated mother. Gunned down while loading groceries into her car"' $A R$, October 21, 1996). 


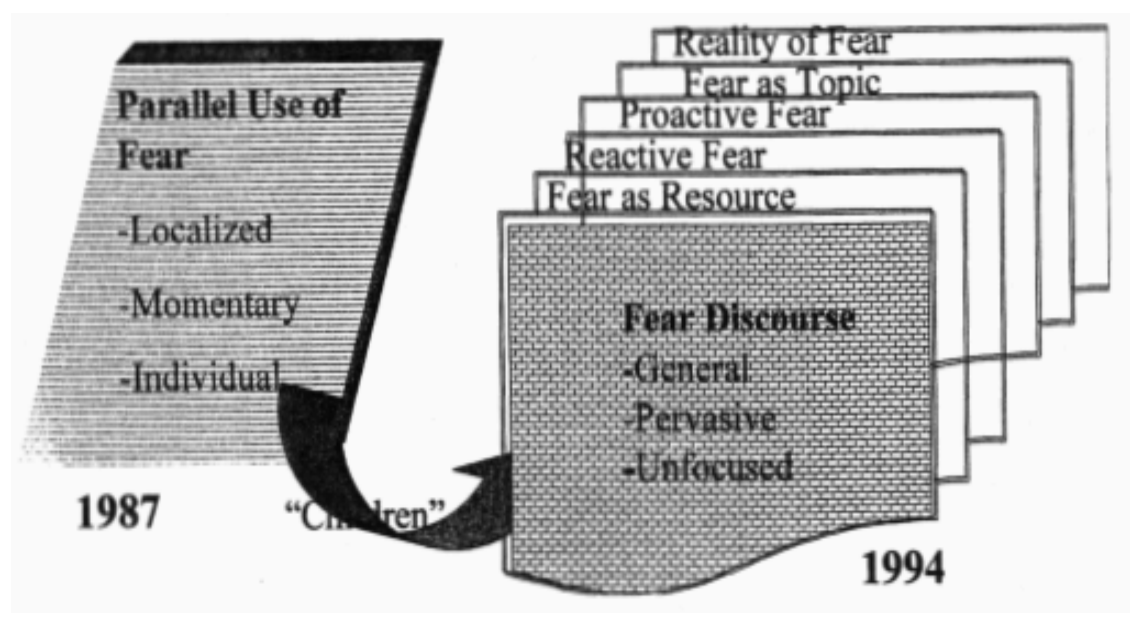

FIGURE 10. AN EMERGING DISCOURSE OF FEAR

The following example shows how fear has come to frame the notion of children and schools, and illustrates the lengths to which school officials must go to abate these fears:

"The academic challenges are being made more difficult by the disturbing presence and growing fear of crime and violence in our schools. To fight back, police forces are beefing up patrols of schools, and nearly 20 percent of surveyed communities now regularly use metal detectors to detect weapons" (AR, November 2, 1994).

Keeping in mind that our focus is on fear rather than, say, "crime," it is helpful to understand how the format of entertaining news embraces reports about fear-as-crime (or children's problems, etc.). Analysis of numerous reports involving fear and the most prominent topics (e.g., crime, violence, and children) suggests that what is thematized as fear depends on what the main "frame" is.

Materials from $L A T$ illustrate the nature and pervasiveness of certain frames. A search for archetypal reports in 1994-1998 with the words "children, school, community, gangs, police, violence, and fear" provided nine articles relevant to the discourse of fear. Examining these articles to ascertain "what's the problem' "who cares/who will benefit' "role of law enforcement' and whether a "social context, e.g., poverty" is discussed, suggests the following.

The common problem is violence, or fear of violence, attributed to gang activity. In five of the nine articles, the emphasis is on gangs as the cause of homicides and not social conditions or conventional conflicts and disputes that are historically associated with urban living. Consistent with the literature, the criminal justice system is both faulted for not doing more and praised as a viable option if more resources were available (Surette 1998). Other articles simply identify fear as the problem. "Gang Turns Hope to Fear" documents the huge growth in a certain gang, producing fear, drug dealing, assaults, robberies, and homicides: "What you get from gangs like 18th Street, on a large scale basis is fear. . an army in the community" (LAT, November 18, 1998, p. Al).

The proposed solutions range from changes in police and prosecution tactics and deployment to gun and drug control to family intervention. Most of the discussion centered around whether or not the police need more money-the 
mayor said "Police can do a better job with existing resources," while others said "the situation will not improve without more resources" (LAT, December 16,1998, p. Al). Police and prosecutors are presented as doing everything they can with the resources they have at their disposal. One police commander commented that "the fact that they continue to come to work day after day is amazing, because they are never going to win" (LAT, December 16, 1996, p. $\mathrm{Al})$. Otherwise, law enforcement is only connected to the problem as the primary solution. The only mention of any related problems is that the gang has its roots in the neighborhood's struggles to achieve economic renewal. This issue is actually introduced not as part of the cause of the growth of the gang, but rather from the victims' perspective. In other words, the gangs mostly victimize the various businesses established in the area by immigrants trying to get ahead: "One of the sad truths of 18th Street's ascendance is that the gang's deepest roots - and its broadest impact - are in neighborhoods struggling to achieve economic renewal" (LAT, November 18, 1998, p. Al).

Several articles suggest a limited contextualization, reflecting popular culture images of gangs, violence, convicts, and poverty. The resources in short supply involve criminal justice agencies and an occasional victim, rather than situating poverty, violence, gangs, and high incarceration rates within a political economy of race and class warfare. Indeed, one article on housing problems reflects an absence of any structural analysis. A dire state of affairs in a housing project is due to the residents' lack of respect for their living conditions. The article cites the housing department's director of housing development as saying that "the fresh surroundings will encourage residents to take pride in - and take care ofthe property" (LAT, May 14, 1995, p. Bl).

Our discussion of themes of fear suggested that the coverage of fear after 1987 moved beyond mere events or specific topics to a more expansive fear frame that is consistent with discursive practices. Within this discourse there are two frames that guide or "screen" fear: "fear as a resource" and "fear as a topic." The former refers to the way in which the meanings of fear are drawn on in order explicitly or implicitly to illustrate or associate an event as an extension of the problem frame (i.e., as something-we-know-about), while the latter examines the character and justification of the way fear is associated with events.

\section{Fear as Resource}

Most articles use "fear as a resource." Consistent with other work on the "problem frame" (Altheide 1997), they incorporate fear with accounts structured as narratives that personify morality plays. The focus is on individual misfortune perpetrated by an evil agent (and/or) who is pursued (or tried or punished) by an agent/agency of righteousness - usually a formal agent of social control (and/or) is celebrated by a member of the chorus (audience) proclaiming their preference for the righteous over the culprit. (It is estimated that law enforcement officers threatened or used force in encounters with more than a half million Americans in 1996 [AR, November 24, 1997, p. A7]). Reactive and proactive fear are two major types.

\section{Reactive Fear}

The majority of topics, problems, and issues presented as "news" involves those framed as "problems." Suffering, misfortune, distress, and inconvenience are the stuff of contemporary news but they are not "the problem." The problem characteristics are part of a format organized around a narrative that begins with a general conclusion that "something is wrong" and we know what it is! The 
focus is on a specific act, but rather the act is embraced as merely an example of a larger more insidious problem - fear. Victims abound. An example of audiences participating in a newspaper's morality play is the following letter to the editor published in the $A R$ on November 16, 1995: The headline reads:

"How Long Must We Live in Place Where Fear is Dictator?"

I was appalled and sickened by the senseless killing of a kind, decent man who did the right thing by helping a trick-or-treater on his own block. A 15year-old who had no business carrying a gun (Does the NRA really support such craziness?) shot him.

I didn't know this 41-year-old humanitarian, but I do know that he could have been me, or my husband, or any one of you. He did what adults are supposed to do: He protected children! He did not cower in a society plagued with violence and fear.

How can we continue to live in our community, where fear is the dictator and love the enemy? How can we raise our children to be decent, helpful human beings if it means them risking their lives?

I am disturbed by the dilemma we face. When an innocent person is killed for doing something good; when teenagers can't go to the mall without fear of being stabbed; when a convicted child molester can write and produce a major motion picture (Powder); and when criminals have more rights than victims, then we must realize it is time for goodness to become militant...

It is as though the audience members - with the aid of editors who select letters to the editor - show their competence by hanging the right script on the fear framework. Thus, something cast as crime or some other subset of evil is acknowledged with an account implicating fear. Taking "common sense" precautions in a changing effective environment may be of interest, but it becomes more relevant and "connected" to other news events about life when it is dropped into the problem frame stressing key elements of the morality play. An excerpt about people's adjustments to "crime" illustrates:

Fear is starting to run our lives . . . They are watching for suspicious motorists and pedestrians, taking the minimum amount of money or credit cards, staking out the safest possible parking space and, along the way, leaving stranded motorists in the dust. (LAT, December 21, 1993, p. El)

Thus, in order to avoid "being victims," people who need assistance are passed by. And victims abound in the problem frame.

\section{Proactive Fear}

Fear as a resource is provided by news organizations that produce reports within the problem frame of the entertainment format. Audience familiarity with a general scenario lends familiarity and credibility to a specific event. Another theme that is less common than reactive fear is connected with victim, but it is in anticipation of some event or activity. The idea here is that one does something in order to avoid being a victim or to avoid engaging in an activity or issue already tainted by fear. Paradoxically, Ferraro (1995, p. 63) notes that when people take steps to alter their lifestyles and avoid situations, they actually increase their perceived risk! Exploring news coverage of such accounts has conceptual relevance for the salience of news reports for individuals' perceptions and 
behavior. There are numerous reports about someone taking proactive or preventive action to shoot or kill, or avoid or leave someone or someplace because they were "in fear of" something. For example, "More than a third of state residents-37 percent-interviewed in a recent poll for The Arizona Republic and KSAZ-TV (Channel 10) said they had changed their routine in the past six months just to reduce their risk of being a crime victim" (AR, May 22, 1994, p. $\mathrm{Al})$.

A discourse of fear is promoted by audience familiarity with and use of the word fear in everyday life. Fear is used as a noun, verb, adjective, and adverb. Fear is increasingly substituted for such words with much different connotations from fear, as "concern," "relevance," "trouble," "query," "issue," "item:' and many others. It is as though the size of the symbolic pot containing fear has expanded exponentially compared to conventional language use; it is more familiar, convenient, and perhaps "more forceful" in making points. Regardless, it has made its mark on news space.

Fear is associated with topics and events that "exist in the space of fear" and are often found in topics-as-headlines (FAT) noted above. A parallel use of fear has also emerged. For example, an article titled, "End Overcrowding, Juvenile Jails Told" (AR, June 24, 1994, p. B4), began “Arizona's juvenile-detention facilities have been ordered by a federal judge to eliminate overcrowding by November, and some officials fear hundreds of youths arrested for violent crimes will be released if no solution is found by the deadline" (emphases added).

Note in this instance that it is neither the "crimes" nor the "youths" that are feared, but their release It is as though the object of the verb (youths) carries weight in deciding what the verb shall be. What amounts to discursive labeling joins the object to the action and ties it together with fear.

\section{Fear as aTopic}

Fear is very rarely treated as a topic. It's brief appearance tends to focus on the way the term and examples are used in news reports, often contrasting either a claim in a news report or a social impact of news reports - such as, fear of crime - with other authoritative standards which may call into question the original concern. These reports tend to be not "news reports" per se but "perspective" pieces, that are very analytical. More often than not, these reports, like most academic analyses of risk, conclude that our society is relatively safe and healthy.

An important part of the context of fear is the world view people have about the danger and riskiness of their lives. We get a lot of reports about risk, and many people take them to heart. Here's one example, with the headline: "What we fear most isn't necessarily what's most dangerous."

"Events that are common in our daily lives are underestimated in terms of the risk they present to us," said Mary Wilson, an assistant professor in Harvard's public-health department.

"Strange and bizarre things that conjure up images of the unknown cause great anxiety."

"We end up spending enormous amounts of money on problems that may pose a trivial risk:'

As Europe forks out $\$ 2 \mathrm{~A}$ billion to defend itself against" mad-cow disease' which may have infected 10 humans, psychologists and riskmanagement experts try to 
understand what makes people afraid. Those fears drive public policy, and picking the "wrong" ones can distract us from bigger killers... HELPLESSNESS FUELS SCARINESS

Risks over which people have no control, or no sense of control, are scarier. Airline passengers feel they can do nothing if their plane crashes. Car drivers can do nothing, either, if they crash into a guardrail at 60 miles an hour, but the sense of being in control is greater behind the wheel. . . "A lot of natural disasters are regular," said psychologist Frederick Koenig at Tulane University in New Orleans. "If you understand what it is, you don't have unstabilized or paralyzing kind of fear:' (AR, April 5, 1996, p. Al)

Thus, analysts revel in noting that one's risk of getting cancer from cigarettes (1 in 3) is seldom at the cognitive forefront as a smoker denounces the lack of police protection in his neighborhood. However, the reports about "fear as a topic" are not consistently presented and rarely occur alongside crime reports.

An exception is illustrated by a front page article in the $A R$ on October 24, 1993, "Crime Wave Across Nation Called a Mirage; Despite Fears, Figures Indicate Rate Isn't Rising," obtained from an affiliated news organization:

Stories of criminal mayhem fill the evening news. Crime sets the agenda for state and local politics from Florida to California. Polls regularly rank crime alongside the economy and health care as the nation's most pressing concerns. . . . The president promises federal action; the first lady declares the fight on crime to be her next big issue. It is as though the country were confronting a devastating new wave of theft and violence.

It isn't. There is no new national crime wave.. . In the words of James Lynch, an American University demographer and crime specialist, "The people who are most anxious are the ones least at risk. Of course, for those places where things are bad, they are bad.

Rare is the confessional such as the one that appeared in the $A R$ on December 27, 1998. Written by a "an elementary school teacher guest columnist:' "Stranger Danger Sometimes Just Plain Hysteria" (p. EV4) described a young mother's concern when she permitted a well-dressed door-todoor sales person-"a young, good-looking man"- to come into her house and clean a spot from her carpet. As the young man worked, she became anxious lest she and her daughter be killed, and took pains to inform the carpet cleaner that her dog "bites all the time." The job finished, the carpet clean, she bought the product, musing, "With no small amount of relief, I showed the young man out the door, peering closely for any distinguishing marks in case I would later need to identify him in a police lineup. Ah, hysteria. As a society, we have become fearful of each other and everyone's motives. Strangers especially. ... Several weeks have passed. No one has broken into our house. Nobody strange has stopped by. Nothing has happened." Nevertheless, we continue to receive a preponderance of news reports about topics that are relatively infrequent, compared to those problems that are more likely to harm us.

This is certainly the case in terms of crime versus cancer. Consider: The death rate alone from cancer in Maricopa County, Arizona, is 121, compared to the crime rate of 88 (both per 100,000 population). But crime is constantly big news, as are the formal agents of social control who claim they can "do something about it," while "soldiers" against cancer receive scant mention. Crime rates have been steadily decreasing in Maricopa County for several years, but the number of news reports about crime has increased. The Maricopa 
County Sheriff, Joe Arpaio, has become a news-household-word in Arizona and much of the country as his "tent-city jail," "posse patrols of mall parking lots:' and other visible "crime fighting" activities are covered by hundreds of news reports. His 85 percent popularity rating according to opinion polls is one of the highest registered by local opinion takers. By contrast, Arizona State University Regents' Professor George Robert Petit barely appears in any news index. He and his cancer research group have discovered natural compounds that have proven in some cases to be 95 percent effective in combating certain kinds of cancer.

\section{CONCLUSION}

Fear is a pervasive word and meaning of everyday life. More and more Americans perceive life to be fearful and risky, particularly due to crime and violence, but a number of other "causes" as well. Examining news reports about fear in The Arizona Republic for a several year period and contrasting these findings with other U.S. newspapers affords an opportunity to assess the character and extent of news coverage pertaining to fear. Casting this inquiry and relevant findings within a theoretical framework about the nature and role of the news media operating in a changing context of an ecology of communication contributes to a more comprehensive awareness of news reports about fear, as well as extends our understanding about the communication process and the role of the news media in creating social reality. This research suggests that fear is not used by itself but is increasingly part of a "discourse of fear:' or a way of focusing on the fear-related features of most events.

A fear perspective is implied with a discourse of fear. Numerous topics and issues are reflected in fear. Indeed, our materials suggest that status dimensions give fear an identity. Race/ethnicity, social class, and gender concerns are implicated with fear, particularly in the context of change and "disorder" in a pluralistic society. The poor, dispossessed, and most recently franchised segments of society are disproportionately associated with the largest fear application - crime.

Several associations are particularly noteworthy. Headlines with the word fear, or Fear-as-Topic (FAT), tends to be associated with children, community, schools, and the police. Frequent associations are related to changing meanings of these words as topics in their own right, as certain kinds of issues, with implications about the source of problems, and perhaps more importantly, the kinds of solutions warranted. Analysis of frequent news topics such as crime, violence, and drugs suggests that crime news and fear news are parallel but different. Fear is more expansive and pervasive than crime, although the former can clearly include the latter. Fear is bigger news than mere crime or even violence. Fear has become a standard feature of news formats steeped in a problem frame oriented to entertainment. Entertainment abhors ambiguity, while truth and effective intervention efforts to improve social life reside in ambiguity. It is this tension between entertaining and familiar news reports, on the one hand, and civic understanding, on the other hand, that remains unresolved.

While our focus was on the role of fear in news reports in The Arizona Republic and several other newspapers, our research design permitted a broader examination of the growing connections between fear and selected topics and issues, including the way in which fear is being used more extensively as a noun, verb, adjective, and adverb. Fear is no longer simply attached in parallel

fashion to a particular event or problem but is used in sweeping, general ways as a topic that surrounds a particular event or problem. We suggested that reports 
involving children, community, and schools illustrate a change in accounts from an emphasis on localized, momentary, and individually experiences to more generalized, pervasive, and unfocused "fear frame." The discourse of fear is often presented as a resource and seldom as a topic, with the former branching into reactive and proactive fear.

Theoretical boundaries are breached when mass media content and forms are part of our everyday lives and contribute to social definitions of self, others, and social issues. Proponents of symbolic interaction, structuralism, cultural studies, and poststructuralism, who are awash in debates about the origin, nature, and consequences of social interaction, are swimming in mass-mediated symbols, from products to information technology to slogans to political tropes and social issues. Words are powerful when they become symbolic frames that direct discursive practices. In an era when information is packaged and manufactured, when popular culture is driven by entertainment formats, and when agents work to transform risks into fear with state-sponsored solutions, the social and the cultural are one. Fear is constructed and it is real. The entertainment inspired frame is embodied in the emotions and justice of everyday life.

Fear is more prevalent in news today than it was several years ago, and it appears in more sections of the newspaper. This is particularly true of headlines. Moreover, tracking the topics with which fear is more closely linked demonstrates that "fear travels" across topics over time, albeit with varying degrees in different news media. Consider the way children are used as symbols.

Topics for public interest are creatively manipulated by various claimsmakers with self-serving interests. The symbolic value of children has risen dramatically in public life. Now virtually everyone wants to "protect children:' and many politicians include children in their rhetoric to justify more formal social control. This extends to the international realm as well. Just prior to the U.S. bombardment of Iraq in 1997, President Clinton argued that it was being done to force Saddam Hussein to comply with international rules. As one writer noted, "He even absurdly brought kids into the equation in the confrontation with Iraq late last year over Saddam Hussein's expulsion of U.N. weapons inspectors. Clinton insisted the inspectors must be allowed to do their jobs because "the safety of the children of the world depends on it." (LAT, June 23, 1998). The U.S. attack, which resulted in many deaths, was justified in order to make the world safer for children. This use of children as part of the justification to "wage war" is in marked contrast to proclamations by antiwar speakers, protesters, and posters during the Vietnam war that "war is not healthy for children and other living things." Obviously, our public discourse has changed. Fear is a "territory" for opening up new connections in public discourse.

Fear is a key element of the effective environment, because it is a major feature of the entertainment format of popular culture in our postjournalism era. Far more is involved than the insights by G. Gerbner and L. Gross (1976) about media contributions to perceptions of a "scary world." Our concern is not merely with media content, or with some public perceptions, although we draw on them in our analysis. Our concern is with identifying a discourse that is pervasive and provides a framework for viewing others and issues alike, for clothing risks and potential danger into a jacket of fear, with one size for all. We want to know how the cloth is tailored, by whom, and with what implications. We have suggested that fear is a larger part of our symbolic landscape at a time when the social terrain is comparatively routine, predictable, and safe. The public increasingly turns to formal agents of social control to "solve the problem" by more force and more prisons. Nearly six million 
Americans - almost 3 percent of the population-are in jail, prison, on probation, or parole. Likewise, formal surveillance pervades our culture through various "testing" mechanisms and visual scrutiny-fifteen million Americans were tested for drugs in 1995-1996. As William G. Staples (1997, p. 130) observes, "Today's culture of surveillance, I would argue, is being built on a foundation of seduction, desire, fear, and salvation." Danger surely lurks in occasional missteps and periodic acts of terror. But danger does not produce a shared environment of fear; we can deal with danger, we can be educated about it, take steps to avoid it or minimize its impact. Danger is not enigmatic. Fear is. Danger does not define an expanding array of news reports. Fear does. Danger can be dealt with one event at a time. Fear cannot. Only by identifying and discussing the processual features of fear as a communicated meaning can we gain a perspective on contemporary life.

\section{ACKNOWLEDGEMENTS}

A draft of this article was presented at the annual meeting of the American Sociological Association, August 2 1-25, 1998, San Francisco. Research support for this project was provided by the Graduate College and the Center for Urban Inquiry at Arizona State University. We acknowledge the research assistance of Barbara Sharp, Enrico Tufano, and Tryon Woods, as well as helpful comments from Richard Ericson, Clinton Sanders, and several reviewers.

\section{REFERENCES}

Altheide, David L. 1976. Creating Reality: How TV News Distorts Events. Beverly Hills, CA: Sage.

1994. "An Ecology of Communication: Toward a Mapping of the Effective Environment."The Sociological Quarterly 35:645-683. 1995. An Ecology of Communication: Cultural Formats of Control. Hawthorne, NY: Aldine de Gruyter. 1996. Qualitative Media Analysis. Newbury Park, CA: Sage.

1997. "The News Media, The Problem Frame, and the Production of Fear." The Sociological Quarterly 38:646-668.

Altheide, David L., and Robert P. Snow. 1991. Media Worlds in the Postjournalism Era. Hawthorne, NY: Aldine de Gruyter.

Aro, Aija R., M. Henriksson, P. Leinikki, and J. Lonnqvist. 1995. "AIDS-Care.” (Supp. 2, Dec.):Pp. 187-197. Helsinki Finland SF-00300: National Public Health Institute Department of Mental Health.

Bailey, Frankie, and Donna Hale. 1998. Popular Culture, Crime, and Justice. Belmont, CA: Westl Wadsworth.

Bennett, W. Lance. 1988. News: The Politics of Illusion. 2d ed. New York: Longman.

Clover, Carol J. 1992. Men, Women and Chain Saws: Gender in the Modern Horror Film. Princeton, NJ: Princeton University Press.

Comstock, George. 1980. Television in America. Beverly Hills, CA: Sage.

Couch, Carl J. 1984. Constructing Civilization. Greenwich, CT: JAI Press.

Crane, Diana. 1992. The Production of Culture. Newbury Park, CA: Sage.

DeFleur, Melvin L, and Sandra Ball-Rokeach. 1982. Theories of Mass Communication. 4th ed. New York: Longman.

Dijk, Teun A. 1988. News as Discourse. Hillsdale, NJ: Lawrence Erlbaum. 
Eco, U. 1979. The Role of the Reader: Explorations in the Semiotics of Texts. Bloomington: Indiana University Press.

Epstein, Edward J. 1973. News from Nowhere. New York: Random House.

Ericson, Richard V., ed. 1995. Crime and the Media. Brookfield, VT: Dartmouth University Press.

Ericson, Richard V., and Kevin D. Haggerty. 1997. Policing the Risk Society. Toronto: University of Toronto Press.

Ericson, Richard V., Patricia M. Baranek, and Janet B. L. Chan. 1989. Negotiating Control: A Study of News Sources. Toronto: University of Toronto Press.

Ferraro, Kenneth F. 1995. Fear of Crime: Interpreting Victimization Risk. Albany: State University of New York Press.

Ferrell, Jeff, and Clinton R. Sanders. 1995. Cultural Criminology. Boston: Northeastern University Press.

Fishman, Mark. 1980. Manufacturing the News. Austin: University of Texas Press.

Fiske, John, and John Hartley. 1978. Reading Television. London: Methuen.

Gerbner, 0, and L. Gross. 1976. "The Scary World of TV's Heavy Viewer.” Psychology Today 9(1 1):41— 45 .

Gerbner, 0., L. Gross, M. Morgan, N. Signorelli, and M. Jackson-Beeck. 1978. "Cultural Indicators:

Violence Profile No. 9." Journal of Communication 28:176-207.

Gitlin, Todd. 1980. The Whole World Is Watching. Berkeley: University of California Press.

Graber, Doris. S. 1984. Processing the News: How People Tame the information Tide. New York:

Longman.

Gunter, Barry. 1987. Television and the Fear of Crime. London: John Libbey.

Hall, Peter M. 1997. 'Meta-Power, Social Organization, and the Shaping of Social Action." Symbolic interaction 20:397-418.

Hall, Stuart. 1977. "Culture, Media, and the Ideological Effect." Pp. 3 15-348 in Mass Communication and Society, edited by M. J. Curran, M. Gurevitch, and J. Wollacott. London: Edward Arnold.

Heath, Linda, and Kevin Gilbert. 1996. "Mass Media and Fear of Crime." American Behavioral Scientist 39:379-386.

Hirsch, Paul. 1980. "The 'Scary World' of the Non-Viewer and Other Anomalies: Are analysis of Gerbner et al. Findings, Part I ." Communication Research 7:403456.

Iyengar, Shanto. 1991. Is Anyone Responsible?: How Television Frames Political issues. Chicago:

University of Chicago Press.

Katz, Jack. 1987. "What Makes Crime 'News'?” Media, Culture and Society 9:47-75.

Kellner, Douglas. 1995. Media Culture: Cultural Studies, identity and Politics between the Modern and Postmodern. New York: Routledge.

Kidd-Hewitt, David, and Richard Osborne. 1995. Crime and the Media: The PostModern Spectacle. London: Pluto Press.

Killias, Martin. 1983. "Review of the Literature; Massenmedien und Kriminalitatsfurcht: Abschied von einer plausiblen Hypothese. Ein selektiver Literaturbericht." Schweizerische-Zeitschriftfur-Soziologie/Revue-Suisse-de-sociologie 9(2):419436.

Lyman, Stanford M. 1997. "The Drama in the Routine: A Prolegomenon to a Praxiological Sociology." Pp. 286-294 in Postmodernism and a Sociology of the Absurd. Fayetteville, AK: The University of Arkansas Press.

MacKuen, M., and S. L. Coombs. 1981. More than News: Media Power in Public Affairs. Beverly Hills, CA: Sage.

Maines, David, and Carl J. Couch, eds. 1988. Communication and Social Structure. Springfield, IL: Charles C. Thomas.

Manning, Peter K. 1998. "Media Loops." Pp. 25-39 in Popular Culture, Crime, and Justice, edited by Frankie Bailey and Donna Hale. Belmont, CA: West/Wadsworth.

Manning, Peter K., and Betsy Cullum-Swan. 1994. "Narrative, Content and Semiotic Analysis:' Pp. 463-484 in Handbook of Qualitative Research, edited by Norman K. Denzin and Yvonna S. Lincoln. Newbury Park, CA: Sage. 
McLuhan, Marshall. 1960. Explorations in Communication. Boston: Beacon Press.

Pfuhl, Erdwin H., Jr., and Stuart Henry. 1993. The Deviance Process. 3rd ed. Hawthorne, NY: Aldine de Gruyter.

Robert, Philippe. 1985. "Insecurite, opinion publique et politique criminelle" (Insecurity, Public Opinion, and Criminal Policy). Annee-Sociologique 35:199-231.

Schlesinger, Philip, Howard Tumber, and Graham Murdock. 1991. "The Media Politics of Crime and Criminal Justice.” British Journal of Sociology 42:397-420.

Shaw, D. L., and M. E. McCombs. 1977. The Emergence of American Political Issues: The Agenda-Setting Function of the Press. St. Paul, MN: West Publishing.

Signorelli, Nancy, and George Gerbner, eds. 1988. Violence and Terror in the Mass Media: An Annotated Bibliography. New York: Greenwood Press.

Signorelli, Nancy, George Gerbner, and Michael Morgan. 1995. "Violence on Television: The Cultural Indicators Project." Journal of Broadcasting and Electronic Media 39:278-283.

Skogan, W., and M. Maxfield. 1981. Coping with Crime. London: Sage.

Snow, Robert P. 1983. Creating Media Culture. Beverly Hills, CA: Sage.

Soubiran, Francine. 1983. "Les Media, vehicule de la peur du crime?" (The Media: Vehicle for Fear of Crime?). Schweizerische-Zeitschr ft-fur-Soziologie/RevueSuisse-de.sociologie 9:407-418.

Sparks, Richard. 1992. Television and the Drama of Crime: Moral Tales and the Place of Crime in Public Life. Milton Keynes, UK: Open University Press.

Staples, William G. 1997. The Culture of Surveillance: Discipline and Social Control in the United States. New York: St. Martin's Press.

Surette, Ray. 1998. Media, Crime and Criminal Justice: Images and Realities. Belmont, CA: West/ Wadsworth.

Taschler-Pollacek, Heidrun, and Helmut Lukesch. 1990. "Viktimisierungsangst als Folge des Fernsehkonsums? Eine Studie an alteren Frauen" (Fear of Victimization as a Consequence of Television Viewing? A Study of Older Women). Publizistik $35: 443-453$.

Tuchman, Gaye. 1978. Making News. New York: Free Press.

Unsworth, Barry. 1995. Morality Play. London: Hamish Hamilton.

Valverde, Monclar-Eduardo. 1995. "Pourquoi craindre Ia communication?" (Why Fear Communication?). Societes 50:441-445.

Warr, Mark. 1980. "The Accuracy of Public Beliefs about Crime." Social Forces 59:456- 470. 1983. "Fear of Victimization: A Look at the Proximate Causes." Social Forces 61:1033- 1043 . 1985. "Fear of Rape Among Urban Women.” Social Problems 32:238-250. 1987. "Fear of Victimization and Sensitivity to Risk." Journal of Quantitative Criminology 3:29- 46.

1990. "Dangerous Situations: Social Context and Fear of Victimization." Social

Forces68:891-907. 1992. "Altruistic Fear of Victimization in Households." Social Science Quarterly 73:723-736.

Willis, William James, and Albert Adelowo Okunade. 1997. Reporting on Risks: The Practice and Ethics of Health and Safety Communication. Westport, CT: Praeger.

Zhondang, P., and G. Kosicki. 1993. "Framing Analysis: An Approach to News Discourse." Political Communication 10:55-69.

Zillman, D., and J. Wakshlag, 1987. "Fear of Victimization and the Appeal of Crime Drama:' in Selective Exposure to Communication, edited by D. Zillman and J. Bryant. Hillsdale, NJ: Lawrence Erlbaum. 